\title{
THE EFFECT OF Fe-Ti INOCULATION ON SOLIDIFICATION, STRUCTURE AND MECHANICAL PROPERTIES OF HIGH CHROMIUM CAST IRON
}

\begin{abstract}
The results of studies of the effect of different amounts of the Fe-Ti inoculant on structure and selected mechanical properties of High Chromium Cast Iron (conventionally abbreviated as HCCI) are presented. The main purpose of the inoculation is structure refinement and hence the improvement of casting properties. Generally considered a strong carbide-forming element, titanium is an effective inoculant for the high chromium cast iron. However, there is an optimal amount of titanium addition beyond which the mechanical properties begin to deteriorate. The studies enabled determining the amount of Fe-Ti inoculant optimal for the cast iron of a given chemical composition.

Keywords: High Chromium Cast Iron, Inoculation, Titanium, Mechanical properties
\end{abstract}

\section{Introduction}

High chromium cast iron (HCCI) belongs to a group of white cast irons. White cast irons have two characteristic features - the colour of casting fracture is close to white, and there is total absence of graphite, while carbon is either bonded in the form of carbide precipitates or dissolved in a matrix $[1,2]$. Containing high levels of chromium, this cast iron offers very good hardenability combined with the resistance to abrasive wear and corrosion, even at high temperature, maintaining - at the same time - satisfactory strength in all the processes where castings experience heavy abrasive wear. Satisfactory functional and mechanical properties are the very reason why high chromium cast iron is widely regarded as a material with the best combination of mechanical properties and wear resistance $[3,4]$.

High chromium cast iron (HCCI) is commonly used in various branches of the industry, and this is mainly due to its resistance to both the abrasive wear and the effect of aggressive environments, including mineral processing, cement production, and pulp and paper industry [5]. High chromium cast iron is divided into hypoeutectic, eutectic and hypereutectic grades. Different properties of these variations depend on the type of generated carbides and also on the type of metal matrix. Hypoeutectic high chromium cast iron is the grade used most widely (especially in the above mentioned technical fields of application), and this fact is due to a relatively high proportional content of the primary austenite grains that improve the plastic properties and corrosion resistance.
Increasing the chromium content changes the structure and properties of chromium carbides from $\mathrm{M}_{3} \mathrm{C}$ to $\mathrm{M}_{7} \mathrm{C}_{3}$ or $\mathrm{M}_{23} \mathrm{C}_{6}$ - where $\mathrm{M}$ is $\mathrm{Cr}, \mathrm{Fe}$ and other elements that may be bonded in carbides [6-10]. Not all carbides have a similar morphology $[11,12]$. Carbides of the $\mathrm{M}_{7} \mathrm{C}_{3}$ type crystallize in the form of isolated precipitates resembling their primary counterparts. Occasionally, however, following the example of eutectic carbides, they tend to form a continuous network in the interdendritic spaces. Carbides of the $\mathrm{M}_{3} \mathrm{C}$ and $\mathrm{M}_{23} \mathrm{C}_{6}$ type occur as interconnected fibres or plates [5-14]. Isolated carbides are more effective in suppressing cracks in a ferritic matrix where they are easily embedded. Among all other chromium carbides, carbides of the $\mathrm{M}_{7} \mathrm{C}_{3}$ type have the highest hardness, thus providing the best protection against abrasive wear [11]. The structure of high chromium cast iron, especially the structure of carbide precipitates, is mainly formed during the process of casting crystallization and cooling. For correct interpretation of changes that occur in the structure of high chromium cast iron during cooling of casting, it is necessary to analyze a ternary system of Fe-Cr-C (Fig. 1), taking, however, into account also other elements that are present in this cast iron and shape its structure. The phase equilibrium diagrams of alloys are the basic tool used for structure interpretation. They illustrate the phase composition of alloys and phase transformations that occur in these alloys as a function of the chemical composition and temperature. Chromium cast iron belongs to the family of casting alloys which through continuous improvement of performance characteristics are increasing their use in various machines and devices. High mechanical and

\footnotetext{
* AGH, UNIVERSITY OF SCIENCE AND TECHNOLOGY, FACULTY OF FOUNDRY ENGINEERING, AL. MICKIEWICZA 30, 30-059, KRAKÓW, POLAND

** ODLEWNIE POLSKIE S.A. BASED IN STARACHOWICE, AL. WYZWOLENIA 70, 27-200 STARACHOWICE, POLAND

\# Corresponding author:
} 
performance properties usually accompany the achievement of optimum microstructure, in particular through the process of melt inoculation. The main objective of this treatment is structure refinement and the related improvement of casting properties. Titanium appears to be a good element for use as an inoculant of the high-quality chromium cast iron [6-10].

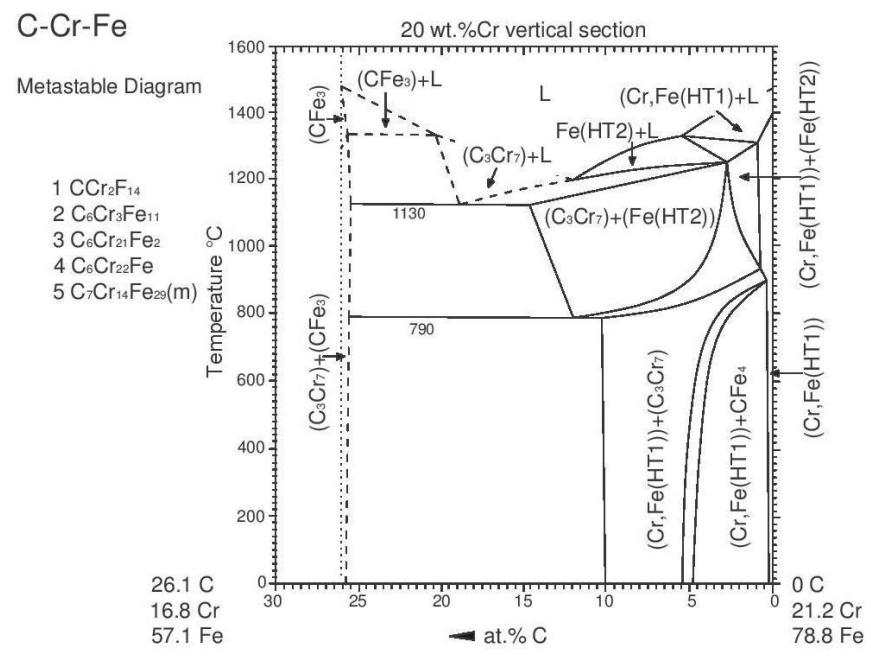

Fig. 1. Phase equilibrium diagram of $\mathrm{Fe}-\mathrm{C}-\mathrm{Cr}$ alloys with a variable content of $\mathrm{Cr}[15]$

Titanium is a strong carbide-forming element. By combining with carbon it forms TiC type carbides. These carbides are characterized by a very high crystallization temperature, which makes them appear as the first phase during cast iron solidification. This results in the formation of pre-eutectic metal matrix reinforced with the $\mathrm{TiC}$ carbide precipitates. TiC carbides may also act as substrates for the nucleation of pre-eutectic austenite phase, inducing in this way the structure refinement. Titanium is one of the inoculants that reduce the nucleus-substrate contact angle and surface tension at the liquid-nucleus interface, consequently reducing the rate of nucleation, which results in higher density of the grains and lower maximum degree of undercooling $\Delta T$.

This research was focused on the effect of varying amounts (weight percent content) of the titanium additive on microstructure and mechanical properties of high chromium cast iron.

\section{Experimental}

The aim of the study was to determine the effect of varying amounts (weight percent content) of the titanium additive on microstructure and mechanical properties of high chromium cast iron. Melting was carried out under industrial conditions at Odlewnie Polskie in Starachowice, while microstructural analysis and testing of mechanical properties were done in a laboratory at the AGH Faculty of Foundry Engineering in Cracow.

Melting was carried out in a $120 \mathrm{~kg}$ capacity induction furnace operating at Odlewnie Polskie in Starachowice. Four melts were made - the first melt had the starting chemical composition and the next three melts were inoculated with different amounts of Fe-Ti addition, i.e. $0.17,0.33$ and $0.66 \mathrm{Fe}-\mathrm{Ti}(\mathrm{wt} \%)$, respectively. The inoculant was introduced to the stream of molten metal in the form of fine particulate. From each melt, $15 \mathrm{~mm}$ diameter rods were cast for testing of the bending strength, and a set of $100 \times 100 \times 30 \mathrm{~mm}$ plates with installed thermocouple for the measurement of temperature recorded with an AGILENT apparatus and analysis of the microstructure. Molten metal was overheated to $1600^{\circ} \mathrm{C}$ and transferred to a $30 \mathrm{~kg}$ capacity ladle from which moulds were next poured. The chemical composition of successive melts is shown in Table 1.

TABLE 1

Chemical composition of melts

\begin{tabular}{|c|c|c|c|c|c|c|c|c|c|c|c|}
\hline \multirow{2}{*}{$\begin{array}{c}\text { Melt } \\
\text { designation }\end{array}$} & \multicolumn{11}{|c|}{ Elements [wt\%] } \\
\hline & $\mathbf{C}$ & $\mathrm{Si}$ & Mn & $\mathbf{P}$ & $S$ & $\mathbf{C r}$ & $\mathrm{Ni}$ & Mo & $\mathrm{Cu}$ & $\mathrm{Ti}$ & $\mathbf{N}$ \\
\hline$+0.0 \% \mathrm{Fe}-\mathrm{Ti}$ & 1.807 & 0.769 & 0.469 & 0.017 & 0.0098 & 21.191 & 0.18 & 0.007 & 0.022 & 0.00356 & 0.06961 \\
\hline$+0.17 \% \mathrm{Fe}-\mathrm{Ti}$ & 1.777 & 0.791 & 0.469 & 0.017 & 0.0098 & 21.216 & 0.181 & 0.008 & 0.027 & 0.0599 & 0.05525 \\
\hline$+0.33 \% \mathrm{Fe}-\mathrm{Ti}$ & 1.77 & 0.768 & 0.417 & 0.019 & 0.0121 & 21.216 & 0.185 & 0.01 & 0.023 & 0.08817 & 0.12644 \\
\hline$+0.66 \% \mathrm{Fe}-\mathrm{Ti}$ & 1.672 & 0.77 & 0.427 & 0.017 & 0.0103 & 21.058 & 0.183 & 0.015 & 0.023 & 0.20431 & 0.13559 \\
\hline
\end{tabular}

\section{Results and discussion}

Each cooling curve has characteristic points corresponding to the extending processes of crystallization phases, in terms of solidification and cooling of the casting. Thanks to this, we can understand the mechanism of crystallization of the alloy, and thereby learn to control it, therefore, it is important to conduct thermal analysis.

For every melt, changes in the temperature were recorded with an AGILENT apparatus. Figures 2-4 show the curves of alloy solidification and cooling.
By definition, the degree of undercooling $\Delta T$, which is the temperature difference between the equilibrium crystallization temperature $T_{r}$ and the actual transformation temperature $T$, is given by equation [26]:

$$
\Delta T=T_{r}-T
$$

Using the potential of computer software to simulate the processes of casting solidification and cooling, a diagram was plotted showing the phase amount-temperature relationship for a ternary system with $1.81 \mathrm{wt} \% \mathrm{C}$ and $21.19 \mathrm{wt} \% \mathrm{Cr}-\mathrm{Fe}$. 


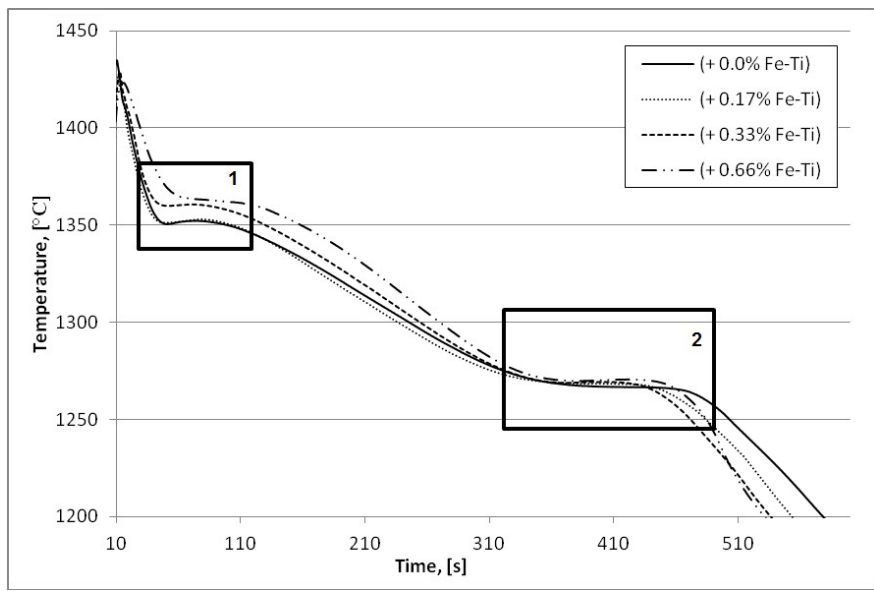

Fig. 2 Solidification and cooling curves of alloys before and after the inoculation with $0.17,0.33$ and 0.66 (wt $\%$ ) of Fe-Ti inoculant. Numbers denote: 1 - the crystallization of primary grains, 2 - the crystallization of carbide eutectic

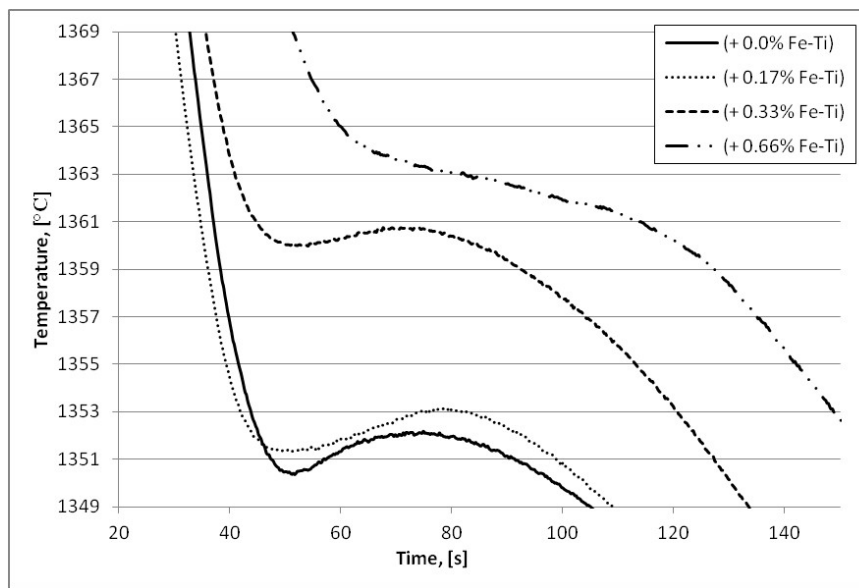

Fig. 3. Crystallization and cooling curves of primary grains (area 1 in Fig. 2)

From the plotted graph, the equilibrium temperature was read for both the primary austenite and eutectic, its values amounting to $1369^{\circ} \mathrm{C}$ and $1300^{\circ} \mathrm{C}$, respectively. Substituting appropriate values into the equation expressing the degree of undercooling $\Delta T$, the following results were obtained:

TABLE 2

Degree of undercooling vs Fe-Ti additions

\begin{tabular}{|c|c|c|c|c|}
\hline \multirow{2}{*}{$\begin{array}{l}\text { Sample } \\
\text { wt } \%\end{array}$} & \multicolumn{2}{|c|}{ Degree of undercooling } & \multicolumn{2}{|c|}{$\begin{array}{c}\text { The difference between } \\
\text { successive melts }\end{array}$} \\
\hline & $\begin{array}{l}\text { primary } \\
\text { grains }\end{array}$ & $\begin{array}{l}\text { carbide } \\
\text { eutectic }\end{array}$ & $\begin{array}{l}\text { primary } \\
\text { grains }\end{array}$ & $\begin{array}{l}\text { carbide } \\
\text { eutectic }\end{array}$ \\
\hline $0.0 \mathrm{Fe}-\mathrm{Ti}$ & 18.5 & 33.5 & - & - \\
\hline $0.17 \mathrm{Fe}-\mathrm{Ti}$ & 17.5 & 31.5 & 1 & 2 \\
\hline $0.33 \mathrm{Fe}-\mathrm{Ti}$ & 9.0 & 31.0 & 8.5 & 0.5 \\
\hline $0.66 \mathrm{Fe}-\mathrm{Ti}$ & 6.0 & 30.3 & 3 & 0.7 \\
\hline
\end{tabular}

From the alloy solidification and cooling curves shown above (Figs. 2-4) and from the calculated values of the degree of undercooling (Table 2) it follows that increasing the tita-

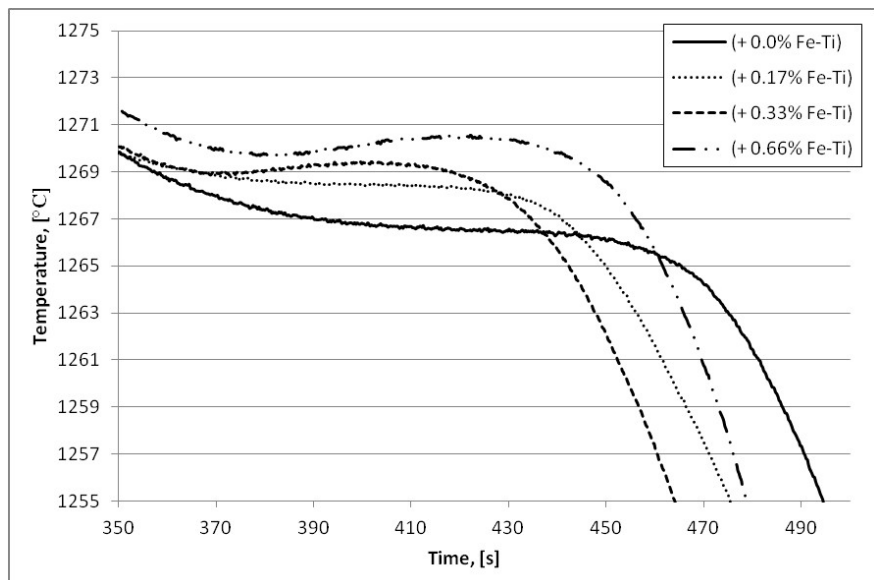

Fig. 4. Crystallization and cooling curves of carbide eutectic (area 2 in Fig. 2)

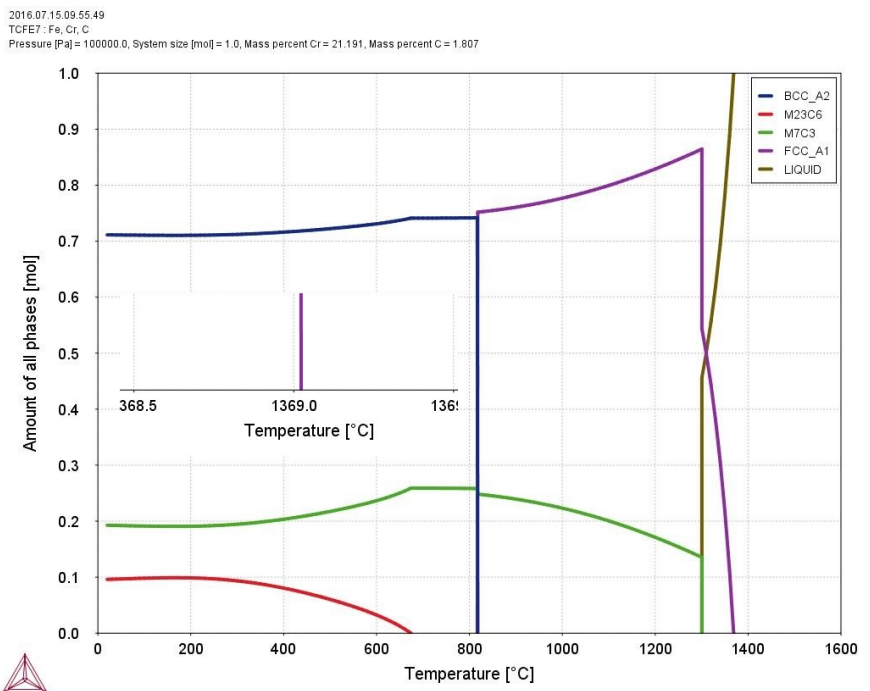

Fig. 5. Diagram showing the phase amount-temperature relationship plotted by the TermoCalc software for a ternary system with $1.81 \mathrm{wt} \% \mathrm{C}$ and $21 / 19 \mathrm{wt} \% \mathrm{Cr}-\mathrm{Fe}$

nium content reduces the degree of undercooling $\Delta T$ for both the primary grains and the eutectic carbide crystallization. It is clear, however, that in the case of the crystallization of primary grains, the difference will be larger. It can be explained by the fact that, relative to the alloy volume, the number of eutectic precipitates present in the alloy is much smaller than that of the primary grains.

Specimens for microstructure examinations were cut out from the cast plates and were subjected to grinding and polishing. The polished metallographic sections were etched with Vilella's reagent. Metallographic analysis was performed using a LEICA MEF-4M optical microscope supported with LEICA-Qwin automatic image processing system. Figure 6 shows the microstructures obtained. Careful examination of these microstructures suggests that the addition of Fe-Ti changes the casting mode of crystallization from exogenous into endogenous. The starting specimen has a clearly oriented structure, while the addition of $\mathrm{Fe}-\mathrm{Ti}$ changes directional crystallization into crystallization in 
a)

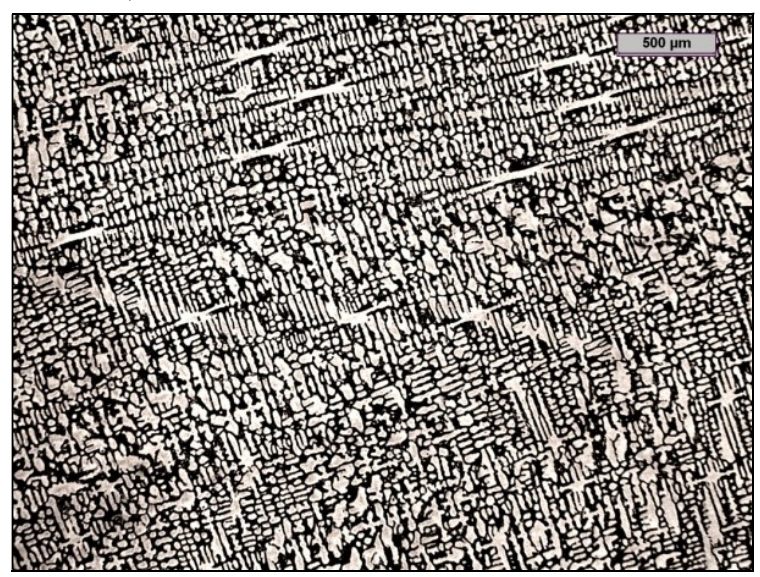

c)

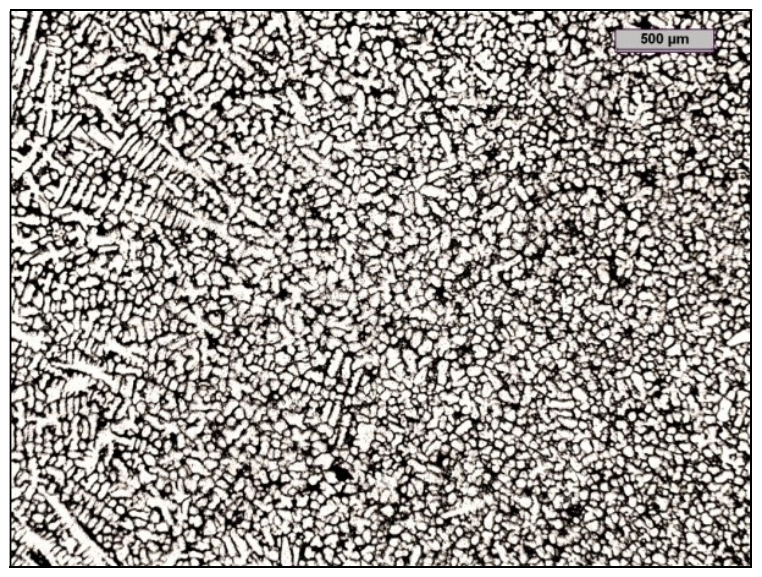

b)

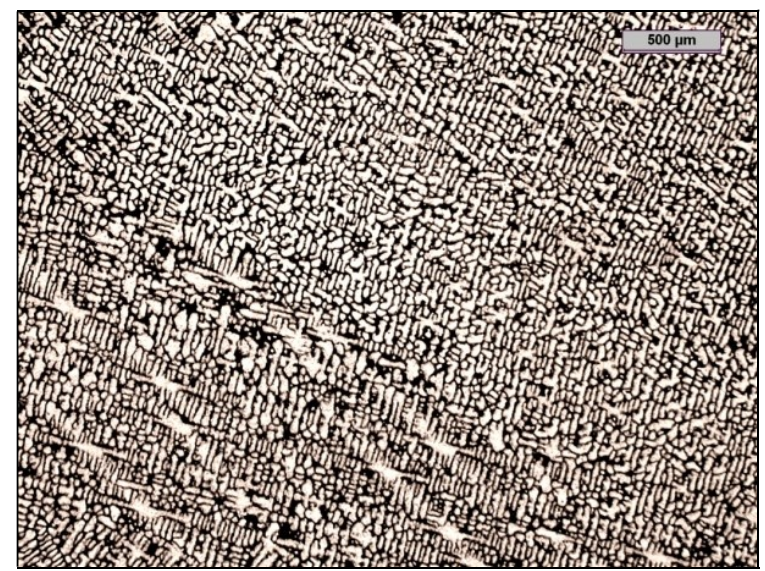

d)

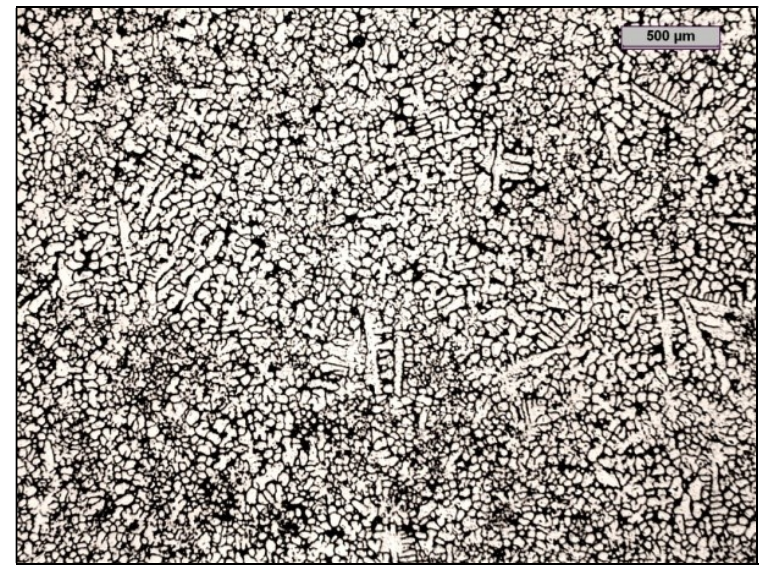

Fig. 6. Microstructure of the metallographic specimens (wt\%): a) - 0.0 Fe-Ti, b) - 0.17 Fe-Ti, c) $-0.33 \mathrm{Fe}-\mathrm{Ti}$, d) $-0.66 \mathrm{Fe}-\mathrm{Ti}$

the entire volume, which is easy to notice in the case of Fe-Ti additions amounting to $0.33 \mathrm{wt} \%$ and $0.66 \mathrm{wt} \%$ (Fig. $6 \mathrm{c}, \mathrm{d}$ ). The next stage of the research has involved the static bending test carried out on the cast rods. Three rods taken from each melt were examined and the averaged results are shown in a graph below (Fig. 7).

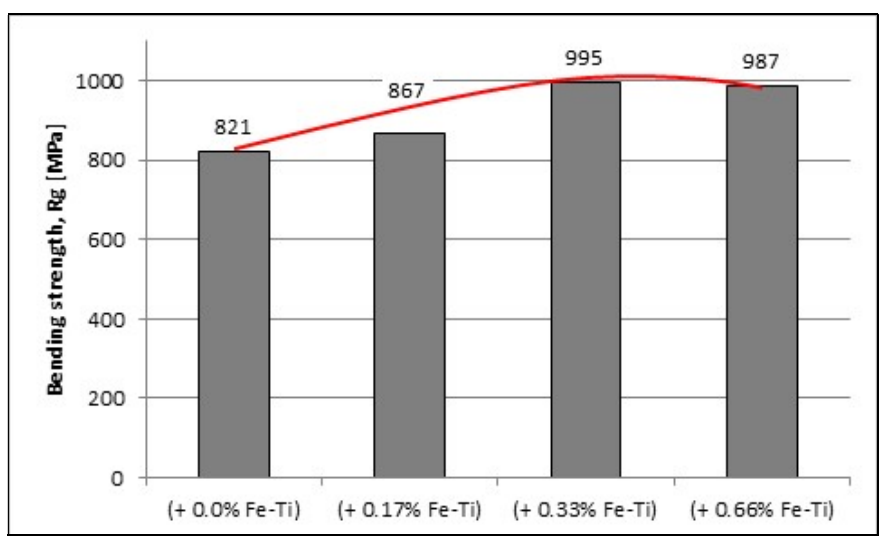

Fig. 7. Bending strength of the examined samples

High values of the bending strength, i.e. ranging from 820 to 1000 [MPa], were obtained. The highest value was obtained for the addition of $0.33 \mathrm{wt} \% \mathrm{Fe}-\mathrm{Ti}$, and the lowest for the starting sample, wherefrom it is clear that the inoculation treatment has been quite effective in the bending strength improvement. The maximum was achieved for a sample containing $0.33 \mathrm{wt} \%$ Fe-Ti; the addition of $0.66 \mathrm{wt} \% \mathrm{Fe}-\mathrm{Ti}$ slightly decreased the bending strength, which might be due to the appearance of an excessive number of carbide precipitates making the matrix unable to withstand any extra load. It has be expected that further increase in titanium content will result in further decrease of the bending strength.

\section{Conclusions}

From the disclosed results it follows that for a given chemical composition, there is a limit on the titanium content beyond which the mechanical properties of high chromium cast iron suffer a drop. In these studies, for the high chromium cast iron containing about $1.7 \mathrm{wt} \% \mathrm{C}$ and $21.2 \mathrm{wt} \% \mathrm{Cr}$, it is the addition of about $0.33 \mathrm{wt} \%$ of Fe-Ti alloy. A correlation has been found between the degree of undercooling $\Delta T$ and strength properties. A large difference in the degree of undercooling $\Delta T$ of austenite grains, occurring between the successive additions of Fe-Ti, makes the bending strength $R_{g}$ increase. On the other hand, for 
melts with the addition of $0.33 \mathrm{wt} \% \mathrm{Fe}-\mathrm{Ti}$ and $0.66 \mathrm{wt} \% \mathrm{Fe}-\mathrm{Ti}$, wherein the difference is 8.5 degrees and 3 degrees in the next melt, the bending strength $R_{g}$ decreases. The analysis of the resulting microstructure shows that the number of the grains of the pre-eutectic austenite which crystallize directionally in the initial melt decreases, and with the increasing titanium content it is the bulk crystallization that starts prevailing in the alloy producing the precipitates of equiaxed grains. This is confirmed by the decreasing value of the degree of undercooling. The change in mechanical properties also depends on the changing type of carbides, but these relationships will be the subject of subsequent studies devoted to the behaviour of primary grains.

\section{Acknowledgements}

The study was co-financed by NCBiR as a targeted project No. PBS / B5/44/2015

\section{REFERENCES}

[1] H.H. Tian, G.R. Addie, K.V. Pagalthivarthi, Determination of wear coefficients for erosive wear prediction through Coriolis wear testing, Wear. 259 (1-6), 160-170 (2005).

[2] Cz. Podrzucki, Cast Iron, 1991 ZG STOP Publication, Krakow.

[3] A. Studnicki, R. Dojka, M. Gromczyk, M. Kondracki, Influence of Titanium on Crystallization and Wear Resistance of High Chromium Cast Iron, Arch. Foundry Eng. 1/16, 117-12 (2016).

[4] O.N. Dogan, J.A. Hawk, G. Laird II, Solidification structure and abrasion resistance of high chromium white irons, Metall. Mater. Trans. A. 128A, 1315-1325 (1997).
[5] D. Kopyciński, E. Guzik, D. Siekaniec, A. Szczęsny, The effect of addition of titanium on the structure and properties of High Chromium Cast Iron, Arch. Foundry Eng. 3/15, 35-38 (2015).

[6] C.P. Tabrett, I.R. Sare, The effect of heat treatment on the abrasion resistance of alloy white irons, Wear. 203, 206-219 (1997).

[7] A. Studnicki, Crystallization temperatures of chromium cast iron in function cooling rate, Arch. Foundry Eng. 48/15, 371-378 (2005).

[8] X.B. Yaer, Erosive wear characteristics of spheroidal carbides cast, Wear. 264 (11-12), 947-957 (2008).

[9] A. Bedolla-Jacuinde, S.L. Aguilar, B. Hernandez, Eutectic modification in a low-chromium white cast iron by a mixture of titanium, rare earths, and bismuth: I. Effect on microstructure, J. Mater. Eng. Perform. 14 (2), 149-157 (2005).

[10] A.B. Jacuinde, W.M. Rainforth, The wear behavior of highchromium white cast irons as a function of silicon and Mischmetal content, Wear. 250, 449-461 (2001).

[11] Y. Matsubara, Solidification and abrasion wear of white cast irons alloyed with $20 \%$ carbide forming elements, Wear. 250, 502-510 (2001).

[12] D. Kopyciński, D. Siekaniec, A. Szczęsny, M. Sokolnicki, A. Nowak, The Althoff-Radtke test adapted for High Chromium Cast Iron, Arch. Foundry Eng. 4/2016, 61-64 (2016).

[13] A. Bedolla-Jacuinde, B. Hernandez, L. Bejar-Gomez, SEM study on the $\mathrm{M} 7 \mathrm{C} 3$ carbide nucleation during eutectic solidification of highchromium white irons, Z. Metallkd. 96 (12), 1380-138 (2005).

[14] A.E. Karantzalis, A. Lekatou, E. Diavati, Effect of Destabilization Heat Treatments on the Microstructure of High chromium Cast Iron: A Microscopy Examination Approach, J. Mater. Eng. Perform. 18 (8), 1078-1085 (2009).

[15] P. Villars, A. Pronce, H. Okamoto, Handbook of Ternary Alloy Phase Diagrams, ASM International 5, 6624 (1995). 